\title{
How do Markets Value Stock Liquidity? Comparative Evidence from the UK, the US, Germany and China
}

\begin{abstract}
We examine the relationship between stock liquidity and returns before, during and after the 20072009 financial crisis. We obtain evidence of a positive association for Germany and the UK, whereas China exhibits the opposite result and the US provides inconclusive evidence.
\end{abstract}

Key words: Liquidity, Stock returns, Amihud Ratio, German Stock Market, UK Stock Market US Stock Market, China Stock Market

JEL Classification: G10, G15. 


\section{Introduction}

Stock liquidity creates firm value by moving capital at a low cost more efficiently to new investments, which improves corporate control and governance for firms (Cheung et al, 2015). These arguments imply that a positive effect of liquidity on changing stock value and returns is expected, particularly when the improvement of cost efficiency for capital movement is valued by stock markets.

The positive association of stock liquidity to the returns is widely evident in the previous academic literature (see among others, Assefa and Mollick (2014)). However, the opposite evidence is also found by studies using different liquidity measures. In the study of illiquidity return premiums using Amihud (2002) to measure illiquidity, Amihud et al (2015) report higher premiums with lower liquidity on average across 43 economies. Prior research - see, among others, Lee (2011) also establishes inconclusive results of the relationship between liquidity and returns.

Unlike previous literature we establish an empirical framework which is robust to outliers and macro shocks whilst eliminating the issues of multicollinearity, autocorrelation and endogeneity. To achieve this, we apply the Asymptotic Principal Component (APC) developed by Korajczyk and Sadka (2008) to extract factors commonly embedded across both liquidity measures and stocks. This analysis enables us to provide accurate estimations of the empirical relationship between stock returns and market liquidity for different countries over various time periods. 
For the second approach to measure market liquidity, we average the liquidity of all stocks excluding one concerning stock as a measure of market liquidity of the concerning stock. Hay and Liu (1998) use this methodology to measure the average output of rival firms. We apply this idea to derive a market liquidity that has a clear exogenous relationship with the returns of the concerning stock, because the stock is dropped from the calculation of the average liquidity of the market.

Using 436,217 observations for the UK, US, German and Chinese stock markets over three time periods (before, during and after the global financial crisis of 2007-2009), we find some very interesting results. We obtain strong evidence of a positive association between returns and liquidity for Germany and the UK. In contrast, China exhibits the opposite result and the US provides inconclusive evidence, possibly caused by significant diversification of value perceptions on liquidity. The findings imply the German and the UK markets are more efficient than the emerging market of China, because liquidity assists capital movement at a low cost.

The rest of this paper is organised in the following way. In the next section we discuss the model specification, section 3 reviews the data, section 4 discusses the empirical results, and section 5 concludes.

\section{Model Specification}

To investigate the stock returns effect of market liquidity, most empirical studies follow a timeseries model introduced by Amihud (2002), 


$$
R_{t}-R_{f}=a_{0}+\theta L_{t-1}+\rho L_{t}^{U N}+\boldsymbol{b} \boldsymbol{X}_{t-1}+\varepsilon_{t}
$$

where $R_{t}$ is the market average stock return of listed firms in month $t . R_{f t}$ is the risk-free rate in month $t . \quad L_{t-1}$ and $L_{t}^{U N}$ are the lagged and unexpected stock market liquidity in month $t-1$ and month $t$, respectively. $\boldsymbol{X}_{\boldsymbol{t}-\mathbf{1}}$ is a vector of other control variables that can affect stock returns. The impact of market liquidity on the market returns is measured by the coefficient $\theta$.

The above model can be extended to the Amihud Commonality-Factor Model in which the market liquidity is defined as the lagged across-measure-and-stock liquidity common factor $\left(L^{C}{ }_{t-1}\right)$, for a market:

$$
R_{t}-R_{f t}=a_{0}+\theta L_{t-1}^{C}+\boldsymbol{b} \boldsymbol{X}_{t-\mathbf{1}}+\varepsilon_{t}
$$

Furthermore, we can expand equation (2) to a panel-data estimation model by estimating the equation below:

$$
R_{i t}=a_{0}+\theta L_{t-1}^{C}+\boldsymbol{b} \boldsymbol{X}_{i t-\mathbf{1}}+F_{i}+\varepsilon_{i t}
$$

where $R_{i t}$ is the returns of stock $i$ in month $t$, and $\boldsymbol{X}_{\boldsymbol{i t}-\mathbf{1}}$ is a vector of one-month lagged firm characteristic variables that control other effects on stock returns. $F_{i}$ and $\varepsilon_{i t}$ are firm dummies and the error term, respectively.

The liquidity commonality factor $L^{C}{ }_{t-1}$ in (3) is calculated on the basis of extracting the common factor of liquidity from three liquidity measures: The transaction cost-based measure (Amihud and 
Mendelson, 1986; Eleswarapu and Reinganum, 1993), the price-based measure of illiquidity ratio (Amihud, 2002), and the volume-based measure (Rouwenhorst, 1999; Jones, 2002; Chan and Faff, 2005; and Koch, 2010).

To test the robustness in the estimation of $L_{t-1}^{C}$ in equation (3), we introduce a new approach to measure market liquidity, which is defined as follows:

$$
\bar{L}_{j t}^{M}=\left(\frac{\sum_{i=1}^{N} L_{i t}-L_{i t}^{M}}{N-1}\right)
$$

Where, using the liquidity measure $\mathrm{M}, \bar{L}_{j t}^{M}$ averages its liquidity of all stocks on the market by excluding the concerning firm $i$ with $-i$ denoting $i$ excluded at time $t$, and $j=-i$ in equation (4). $\mathrm{N}$ is the number of trading days in month $t$. Since stock $i$ is excluded from the computation, we refer to the average as the rival average of liquidity for stock $i$. To test the robustness of estimation of the $L_{t-1}^{C}$ in equation (3), we replace it with $\bar{L}_{-i t}^{M}$ to obtain the model in equation (5):

$$
R_{i t}=a_{0}+\lambda \bar{L}_{j t}^{M}+\boldsymbol{b} \boldsymbol{X}_{i t-1}+F_{i}+\varepsilon_{i t}
$$

The rival average of liquidity $\bar{L}_{j t}^{M}$ brings two advantages in the estimation of equation (5). First, it enables full panel estimation of the market liquidity effect on the returns using a large sample, which will be more informatively robust. Second, we treat $\bar{L}_{j t}^{M}$ as exogenous in relation to the estimation of the returns $\mathrm{R}_{\mathrm{it}}$ since $\bar{L}_{j t}^{M}$ excludes information of stock $i$. Empirically, a liquidity measure M is applied for computing $\bar{L}_{j t}^{M}$ in model (4). This is based on the Quoted Proportional Spread of illiquidity ( $L_{i t}^{S}$ ) that encapsulates illiquidity in contrast to $L^{C}{ }_{t-1}$ in equation (3) that 
picks up liquidity. The two opposite measurements of liquidity each provide us with a mirror estimation with each other, so that we can test the robustness of estimation.

One particular problem we encounter is that market liquidity and macroeconomic shocks can result in biased estimation of the market liquidity on the returns if the control of the shocks is omitted in the estimation. In order to separate the liquidity effect from macroeconomic shocks, we introduce a time dummy in the estimation of equations (3) and (5):

$$
\begin{aligned}
& R_{i t}=a_{0}+\theta L_{t-1}^{C}+\boldsymbol{b} \boldsymbol{X}_{i t-\mathbf{1}}+F_{i}+D_{T}+\varepsilon_{i t} \\
& R_{i t}=a_{0}+\lambda \bar{L}_{j t-1}^{M}+\boldsymbol{b} \boldsymbol{X}_{i t-1}+F_{i}+D_{T}+\varepsilon_{i t}
\end{aligned}
$$

where $D_{T}$ is a time dummy to control the effect of macroeconomic shocks that can usually last over a year $T$. To mitigate the effect of the multicollinearity between the year dummy and the market liquidity in the estimation of equations (6.1) and (6.2), we replace the level-based $L_{t-1}^{C}$ or $\bar{L}_{j t-1}^{M}$ with their first difference of $\Delta L_{t-1}^{C}$ and $\Delta \bar{L}_{j t-1}^{M}$, respectively: see below.

$$
\begin{aligned}
& R_{i t}=a_{0}+\theta \Delta L_{t-1}^{C}+\boldsymbol{b} \boldsymbol{X}_{i t-\mathbf{1}}+F_{i}+D_{T}+\varepsilon_{i t} \\
& R_{i t}=a_{0}+\lambda \Delta \bar{L}_{j t-1}^{M}+\boldsymbol{b} \boldsymbol{X}_{i t-\mathbf{1}}+F_{i}+D_{T}+\varepsilon_{i t}
\end{aligned}
$$

Having controlled for both stock/firm-specific effects and macro shocks, the estimation of equations (6.1), (6.2) and (7.1) and (7.2) for $\theta$ and $\lambda$ captures the effect of the liquidity on the stock 
returns. In addition, the January effects emphasised by Amihud (2002) are taken into account in our empirical estimations. ${ }^{1}$

\section{Data Sample and Descriptive Statistics}

All company stocks listed in the NYSE and the German, London and Chinese (Shanghai and Shenzhen) Stock Exchanges are collected from Bloomberg over the time period 2001-2013. We acquire daily information on stock, bid, ask prices, trading volume, shares outstanding, and market capitalisation. Firms categorised as Funds, ADRs, Units and REITs are excluded from our sample. In total, our robust sample has 436,217 observations for four economies over 144 months. We estimate the liquidity and returns relationship before (2002-2006), during (2007-2009) and post (2010-2013) the financial crisis.

\section{Estimation and Discussion}

The summary report displayed in Table 1 allows us to directly compare our 30 estimated empirical relationships across different time periods and estimation methods for each market. In total we have 120 findings for four economies. $\lambda$ is the marginal return effect of illiquidity and $\theta$ represents the marginal return effect of liquidity. These two estimated coefficients are expected to be significantly opposite to their signs if estimates are consistent and robust. When this expectation is shown in our estimation, we call it 'strong' evidence; otherwise, it is 'weak evidence' if one

\footnotetext{
${ }^{1}$ We calculate individual stock liquidity using the transaction cost measured established by Amihud and Mendelson (1986), the price-based measure founded by Amihud (2002) and the volume-based measure used by various authors such as Chan and Faff (2005). We measure market liquidity by deriving the common factor of liquidity by following the APC approach. We use the quoted proportional spread of illiquidity to represent the rival average of liquidity. Finally, we compute monthly stock returns using the standard relative price approach, volatility using the standard deviation, firm size using market capitalisation, and momentum using Carhart (1997) and Amihud (2002).
} 
estimated coefficient is significant. However, a coefficient without significance, or one that is 'inconclusive', arises when both estimated coefficients are significant but their estimated signs are contradictory - for instance, both have the same sign.

\section{$\underline{\text { Germany }}$}

The comparative estimates of $\theta$ and $\lambda$ show strong evidence for Germany in the pre-crisis and during-crisis periods that liquidity positively affects the returns, but show weak evidence to support this pattern for the post-crisis period. As a result, overall, we claim that Germany has a persistently consistent pattern of improvement in market liquidity valued positively for stock investment which increases the returns over time.

\section{$\underline{\text { The UK }}$}

A positive effect of liquidity is found on the returns for the pre-crisis period, supported by strong evidence shown in the fourth and fifth rows of estimated $\lambda$ and $\theta$, Table 1 . During the financial crisis there is also strong evidence shown in the fifth row for the post-crisis period, while weak evidence is shown in the fourth and fifth rows. On the basis of this evidence, we claim that the UK has a similar pattern to Germany; that is, a persistently consistent pattern of improvement of market liquidity valued positively for stock investment over time.

\section{The USA}

In the third, fourth and fifth rows of the US Panel of Table 1 , we find that the estimated $\lambda$ and $\theta$ are significantly opposite to each other, providing strong evidence for the negative effect of liquidity on the returns for the pre-crisis period. This finding has not been extended to the duringcrisis and the post-crisis periods, since estimated $\lambda$ and $\theta$ in the same rows show inconclusive 
findings for these two periods. Clearly, the evidence here concludes that the US market is inconclusive in terms of the liquidity effect on the returns, because the value perception on liquidity for investment is not dominated by a particular bias over time.

\section{$\underline{\text { China }}$}

As the largest emerging market in the world, how does China perceive liquidity for stock investment? Interestingly, the Chinese market values market illiquidity for higher investment premiums persistently over time. The finding on the negative relation is supported by strong evidence present in all three time periods. This can be witnessed in the estimated positive $\lambda$ and negative $\theta$ in the third, fourth and fifth rows of the China Panel of Table 1. This pattern is a consistent reiteration of our finding for China's negative effect of liquidity on the returns.

\section{[INSERT TABLE 1 HERE]}

\section{Conclusions}

In this paper we examine the empirical relationship between stock market liquidity and returns before, during and after the global financial crisis of 2007-2009. We identify strong evidence that the German and UK markets consistently exhibit a positive pattern of liquidity in relation to the returns across the three examined time periods. In contrast, the Chinese market has the opposite effect, given that we discover a very dominant negative pattern across the three time periods. Interestingly, as the largest stock market in the world, the US yields inconclusive evidence regarding the association between liquidity and stock returns. A possible cause of this result could be the significant diversification of value perception on liquidity. 


\section{References}

Amihud. Y. (2002). 'Illiquidity and Stock Returns: Cross-section and Time-series Effects', Journal of Financial Markets, 5, 31-56.

Amihud, Y., and Mendelson, H., (1986). 'Asset Pricing and the Bid-ask Spread', Journal of Financial Economics, 17, pp. 223-249.

Amihud, Y., Hameed, A., Kang, W. and Zhang, H. (2015) ‘The illiquidity premium: international evidence’, Journal of Financial Economics, 117, 350-368.

Assefa, T. A. and Mollick, A. V. (2014). African stock market returns and liquidity premia. Journal of International Financial Markets, Institutions and Money, 32, 325-342.

Carhart, M. M. (1997). 'On persistence in mutual fund performance'. The Journal of Finance, 52(1), 5782.

Chan, H. W. and Faff, R. W. (2005). 'Asset pricing and the illiquidity premium’. Financial Review, 40(4), 429-458.

Cheung, W., Chung, R. and Fung, S. (2015). 'The Effects of Stock Liquidity on Firm Value and Corporate Governance: Endogeneity and the REIT Experiment'. Journal of Corporate Finance, 35, 211-231.

Eleswarapu, V. R. and Reinganum, M. R. (1993). 'The seasonal behavior of the liquidity premium in asset pricing'. Journal of Financial Economics, 34(3), 373-386.

Hay, D. A. and Liu, G. S. (1998). 'The Investment Behaviour of Firms in an Oligopolistic Setting'. Journal of Industrial Economics, 46(1), 79-99.

Jones, C.M. (2002). A century of stock market liquidity and trading costs. Graduate School of Business, Columbia University.

Koch, S. (2010). 'Illiquidity and stock returns: Evidence from the German stock market'. Available at SSRN 1646859.

Korajczyk, R. A., and Sadka, R. (2008). 'Pricing the commonality across alternative measures of liquidity'. Journal of Financial Economics, 87(1), 45-72.

Lee, K. H. (2011). 'The world price of liquidity risk'. Journal of Financial Economics, 99(1), 136-161.

Rouwenhorst, K. G. (1999). 'Local return factors and turnover in emerging stock markets'. The Journal of Finance, 54(4), 1439-1464.

Table 1 How does market liquidity affect the returns? A summary report on estimated $\lambda$ and $\boldsymbol{\theta}$

\begin{tabular}{|c|c|c|c|c|c|c|}
\hline & \multicolumn{2}{|c|}{ Pre-crisis: 2002-2006 } & \multicolumn{2}{|c|}{ During-Crisis: 2007-2009 } & \multicolumn{2}{|c|}{ Post-crisis: 2010-2013 } \\
\hline & $\begin{array}{c}\text { Rival } \\
\text { average of } \\
\text { illiquidity } \\
\Lambda\end{array}$ & $\begin{array}{l}\text { Common-factor } \\
\text { of liquidity } \\
\theta\end{array}$ & $\begin{array}{c}\text { Rival average } \\
\text { of illiquidity } \\
\lambda\end{array}$ & $\begin{array}{c}\text { Common-factor } \\
\text { of liquidity } \\
\theta\end{array}$ & $\begin{array}{l}\text { Rival } \\
\text { average of } \\
\text { illiquidity } \\
\quad \lambda\end{array}$ & $\begin{array}{l}\text { Common- } \\
\text { factor of } \\
\text { liquidity } \\
\quad \theta\end{array}$ \\
\hline \multicolumn{7}{|c|}{ Germany } \\
\hline \multirow{2}{*}{$\begin{array}{l}\text { Without control of } \\
\text { macro shocks }\end{array}$} & $-0.0731^{* * *}$ & $0.125^{* * *}$ & $-0.0627 * * *$ & $0.0674 * * *$ & $0.0783^{* * *}$ & $-0.384 * * *$ \\
\hline & 25,448 & 25,448 & 16,712 & 16,712 & 17,795 & 17,795 \\
\hline Control of macro & 0.00171 & $-0.107 * * *$ & $0.0216^{*}$ & $-0.0560 *$ & $0.0844^{* * *}$ & $-0.447 * * *$ \\
\hline \multicolumn{7}{|c|}{10} \\
\hline
\end{tabular}




\begin{tabular}{|c|c|c|c|c|c|c|}
\hline shocks by yr dummy & 25,448 & 25,448 & 16,712 & 16,712 & 17,795 & 17,795 \\
\hline \multirow{2}{*}{$\begin{array}{l}\text { Control macro shock } \\
\text { and multicollinearity }\end{array}$} & -0.0252 & $0.358 * * *$ & $-0.0431 *$ & $0.204^{* * * *}$ & $-0.143 * * *$ & -0.100 \\
\hline & 24,278 & 24,278 & 16,222 & 16,222 & 17,317 & 17,317 \\
\hline \multirow{2}{*}{$\begin{array}{l}\text { Control macro shock } \\
\text { and multicollinearity } \\
\text { and January effect }\end{array}$} & $-0.0696 * * *$ & $0.414^{* * *}$ & $-0.0859 * * *$ & $0.155^{* * *}$ & $-0.139 * * *$ & -0.0986 \\
\hline & 23,113 & 23,113 & 15,346 & 15,346 & 15,862 & 15,862 \\
\hline \multirow{2}{*}{$\begin{array}{l}\text { Control macro shock } \\
\text { and multicol. and } \\
\text { Jan eff } \\
\text { and instrument } \\
\text { R100 } \\
\text { it-1 }\end{array}$} & $-0.0776 * * *$ & $0.428 * * *$ & $-0.0818 * * *$ & $0.118 * *$ & $-0.137 * * *$ & -0.0928 \\
\hline & 23,113 & 23,113 & 15,346 & 15,346 & 15,862 & 15,862 \\
\hline
\end{tabular}

The UK

\begin{tabular}{|c|c|c|c|c|c|c|}
\hline \multirow{2}{*}{$\begin{array}{l}\text { Without control of } \\
\text { macro shocks }\end{array}$} & $-0.0346 * * *$ & $0.137 * * *$ & $0.0327 * * *$ & $-0.274 * * *$ & $0.0541 * * *$ & 0.0123 \\
\hline & 26,515 & 26,515 & 15,194 & 15,194 & 17,846 & 17,846 \\
\hline \multirow{2}{*}{$\begin{array}{l}\text { Control of macro } \\
\text { shocks by yr dummy }\end{array}$} & $0.0615 * * *$ & -0.0315 & -0.00097 & $-0.190 * * *$ & $0.0727 * * *$ & $-0.370 * * *$ \\
\hline & 26,515 & 26,515 & 15,194 & 15,194 & 17,846 & 17,846 \\
\hline \multirow{2}{*}{$\begin{array}{l}\text { Control macro shock } \\
\text { and multicollinearity }\end{array}$} & 0.00036 & $0.178 * * *$ & $-0.0951^{* * *}$ & 0.0609 & $\begin{array}{c}- \\
0.0509 * * *\end{array}$ & $0.155^{* * *}$ \\
\hline & 25,251 & 25,251 & 14,753 & 14,753 & 17,259 & 17,259 \\
\hline \multirow{2}{*}{$\begin{array}{l}\text { Control macro shock } \\
\text { and multicollinearity } \\
\text { and January effect }\end{array}$} & $-0.0822 * * *$ & $0.0758 * *$ & $-0.1000 * * *$ & 0.0705 & $\begin{array}{c}- \\
0.0760 * * *\end{array}$ & 0.0867 \\
\hline & 23,781 & 23,781 & 14,301 & 14,301 & 15,924 & 15,924 \\
\hline \multirow{2}{*}{$\begin{array}{l}\text { Control macro shock } \\
\text { and multicol. and } \\
\text { Jan eff and } \\
\text { instrument } \mathrm{R} 100_{\text {it-1 }}\end{array}$} & $-0.0899 * * *$ & $0.0956 * * *$ & $-0.105 * * *$ & $0.133 * *$ & $-0.0703 * * *$ & 0.0656 \\
\hline & 23,781 & 23,781 & 14,301 & 14,301 & 15,924 & 15,924 \\
\hline
\end{tabular}

The US

\begin{tabular}{|c|c|c|c|c|c|c|}
\hline \multirow{2}{*}{$\begin{array}{l}\text { Without control of } \\
\text { macro shocks }\end{array}$} & $0.0599 * * *$ & $-0.291 * * *$ & $0.00563 * * *$ & $-0.196 * * *$ & $0.0271 * * *$ & $-1.467 * * *$ \\
\hline & 70,016 & 70,016 & 39,478 & 39,478 & 56,463 & 56,463 \\
\hline \multirow{2}{*}{$\begin{array}{l}\text { Control of macro } \\
\text { shocks by yr dummy }\end{array}$} & $0.0735 * * *$ & $-0.389 * * *$ & -0.00065 & $-0.0586 * * *$ & $0.0158 * * *$ & $-1.173 * * *$ \\
\hline & 70,016 & 70,016 & 39,478 & 39,478 & 56,463 & 56,463 \\
\hline \multirow{2}{*}{$\begin{array}{l}\text { Control macro shock } \\
\text { and multicollinearity }\end{array}$} & $0.0172 * * *$ & $-0.0474 * *$ & $-0.0665 * * *$ & $-0.824 * * *$ & $-0.0216 * * *$ & $-2.436 * * *$ \\
\hline & 67,196 & 67,196 & 38,522 & 38,522 & 55,344 & 55,344 \\
\hline \multirow{2}{*}{$\begin{array}{l}\text { Control macro shock } \\
\text { and multicollinearity } \\
\text { and January effect }\end{array}$} & $0.0252 * * *$ & $-0.0728 * * *$ & $-0.0699 * * *$ & $-1.194^{* * *}$ & $-0.0230 * * *$ & $-2.790 * * *$ \\
\hline & 62,803 & 62,803 & 35,214 & 35,214 & 50,700 & 50,700 \\
\hline \multirow{2}{*}{$\begin{array}{l}\text { Control macro shock } \\
\text { and multicol. and Jan } \\
\text { eff } \\
\text { and instrumental } \\
\qquad \mathrm{R} 100_{\text {it-1 }}\end{array}$} & $0.0235^{* * *}$ & $-0.0602 * * *$ & $-0.0751 * * *$ & $-1.176^{* * *}$ & $-0.0226 * * *$ & $-2.867 * * *$ \\
\hline & 62,803 & 62,803 & 35,214 & 35,214 & 50,700 & 50,700 \\
\hline
\end{tabular}

\section{China}

\begin{tabular}{l|c|c|c|c|c|c}
\hline \multirow{2}{*}{$\begin{array}{l}\text { Without control of } \\
\text { macro shocks }\end{array}$} & $-0.0327^{* * *}$ & $0.135^{* * *}$ & $-0.0602 * * *$ & $0.574^{* * *}$ & $0.0926 * * *$ & $-0.453^{* * *}$ \\
\cline { 2 - 7 } & 49,539 & 49,539 & 34,013 & 34,013 & 67,198 & 67,198 \\
\hline
\end{tabular}




\begin{tabular}{l|c|c|c|c|c|c}
\hline \multirow{2}{*}{$\begin{array}{l}\text { Control of macro } \\
\text { shocks by yr dummy }\end{array}$} & $0.0204 * * *$ & $-0.0667 * * *$ & $0.0646 * * *$ & $-0.249 * * *$ & $0.183 * * *$ & $-0.929 * * *$ \\
\cline { 2 - 7 } & 49,539 & 49,539 & 34,013 & 34,013 & 67,198 & 67,198 \\
\hline $\begin{array}{l}\text { Control macro shock } \\
\text { and multicollinearity }\end{array}$ & $0.0328 * * *$ & $-0.0541 * * *$ & $0.273 * * *$ & $-0.654 * * *$ & $0.0914 * * *$ & $-0.399 * * *$ \\
\cline { 2 - 7 } & 46,968 & 46,968 & 32,621 & 32,621 & 64,790 & 64,790 \\
\hline $\begin{array}{l}\text { Control macro shock } \\
\text { and multicollinearity }\end{array}$ & $0.0890 * * *$ & $-0.238 * * *$ & $0.308 * * *$ & $-0.684 * * *$ & $0.107 * * *$ & $-0.702 * * *$ \\
\cline { 2 - 7 } and January effect & 43,766 & 43,766 & 30,272 & 30,272 & 61,174 & 61,174 \\
\hline $\begin{array}{l}\text { Control macro shock } \\
\text { and multicol. and Jan } \\
\text { eff }\end{array}$ & $0.0886 * * *$ & $-0.226 * * *$ & $0.252 * * *$ & $-0.558 * * *$ & $0.123 * * *$ & $-0.771 * * *$ \\
\cline { 2 - 7 } & & & & & & \\
and instrumental & 43,766 & 43,766 & 30,272 & 30,272 & 61,174 & 61,174 \\
\hline
\end{tabular}

Notes: The reported figures are the estimated $\lambda$ as the marginal return effect of market illiquidity and estimated $\theta$ as the marginal return effect of market liquidity, and their corresponding observations used for the estimation. The empirical estimation has five rows representing five different methods of investigation for each market. The fifth row of 'Control of macro shocks and multicol and jan eff and instrumental R100 ${ }_{\text {it-1' }}$ means we have controlled for the macro shocks, multicollinearity effect and the January effect in estimation together with use of the instrumental variable R100 $0_{\text {it-1 }}$ for estimation. 